\title{
Public support to firm-level innovation: An evaluation of the FONTAR program
}

Apoyo público a la innovación de las firmas: Una evaluación del FONTAR

\author{
MARIANo PEREIRA* \\ Julí́N MARTÍNEZ CORREA** \\ GABRIEL SCATTOLO***
}

\begin{abstract}
This paper studies the impact of non-refundable grants (NRG) of the Argentinean Technological Fund (FONTAR) on firms' innovative efforts and performance. We use a panel database of 954 firms that applied for public support to innovate during the period 2007-2013. Using a difference-in-differences approach, our results show that the NRG have a positive effect on firms' innovative intensity, considering both the innovation activities to sales ratio and $R \& D$ to sales ratio. These remain robust to alternative definitions of control group and the outcome variable. Analysis of heterogeneous effects reveals that the impact was exclusively concentrated on small and young firms.
\end{abstract}

Key words: Innovation, impact evaluation, Argentina.

JEL Classification: O32, 038, C23.

\section{Resumen}

Este trabajo analiza el impacto de los aportes no reembolsabes (ANR) del Fondo Tecnológico Argentino (FONTAR) sobre el esfuerzo y desempeño en innovación de las firmas. Usamos un panel de 954 empresas que solicitaron apoyo público para innovar durante el período 2007-2013. Utilizando un enfoque de diferencias-en-diferencias, nuestros resultados muestran que los ANR tienen un efecto positivo en la intensidad innovadora de las firmas, considerando tanto el ratio de actividades de innovación sobre ventas como el de gastos de

* (UNGS-CIECTI). E-mail: mpereira@ ciecti.org.ar

** (UNLP-CIECTI). E-mail: julian.martinezcorrea@gmail.com

***(UNLP). E-mail: gabrielscattolo@gmail.com

Received: 19 de octubre de 2017. Accepted: 31 de mayo de 2018. 
I $+D$ sobre ventas. Estos resultados son robustos a definiciones alternativas de grupo de control y variables de resultados. El análisis de efectos heterogéneos revela que estos provienen exclusivamente de las empresas jóvenes y pequeñas.

Palabras clave: Innovación, evaluación de impacto, Argentina.

Clasificación JEL: O32, 038, C23.

\section{INTRODUCTION}

Innovation and technological improvement at the firm level are essential aspects of national economic growth (Aghion and Howitt, 1990; Grossman and Helpman, 1991; Romer, 1990). Thus, promotion of research and development (R\&D) has become one of the pillars of public policies focused on foster productivity in developed and low/middle-income countries. In this context, low participation of Latin America's private sector in R\&D expenditures has become a signal of concern that has led governments to boost innovation investment through a wide range of instruments (Crespi et al., 2014).

The Argentinean Technological Fund (hereinafter referred to as FONTAR, the Spanish acronym for its name) is the country's main source of public funding for innovation at the firm level in terms of both the number of instruments and the amount of the grants (Porta and Lugones 2011). It is administered by the National Agency for Scientific and Technological Promotion (hereinafter referred to as ANPCyT, the Spanish acronym for its name), which depends on the National Ministry of Science and Technology and Productive Innovation (hereinafter referred to as MINCyT, the Spanish acronym for its name). Three types of instruments compound the fund: non-refundable grants, tax credit, and subsidized loans (NRG, TC and SL, respectively). The purpose of this policy is to foster innovation in the wide sense, which implies that firms can apply with projects based exclusively on R\&D activities but also with technological upgrade projects based mainly on the acquisition of capital goods and the training of the human resources.

The literature review about the effect of FONTAR indicates that impact evaluations are scarce and focalized in benefits adjudicated before the 2000s (Binelli and Maffioli, 2007; Chudnovsky et al., 2006 and López et al., 2010). From an aggregated view, these articles show that FONTAR has been effective in promoting the investment on R\&D and total innovation activities measured in absolute terms, but not when is measured in relative terms. Moreover, the evidence does not confirm the existence of input additionality and long-term effects on firm's productive performance. Moreover, the heterogeneous effects of the program have not been analyzed previously.

In this paper we focus on the impact of the NRG instrument administered by FONTAR. Specifically, we evaluate the effect of these subsidies on innovation intensity and innovative performance. To estimate the causal effects, we use a 
difference-in-differences approach that allows us to remove bias due to fixed effects at the firm level (observable and unobservable cofounders). We have a unique database built from innovation surveys of the ANPCyT with information for the period 2007-2013 which includes firms that applied for a public support of FONTAR (were they granted or not). The treatment group is composed by firms that were beneficiaries just through NRG, while the control group includes firms that applied for a public support (NRG, TC or SL) and were rejected.

Our results show that the program has a positive and significant effect on innovation intensity, considering both the innovation activities to sales ratio as well as the R\&D to sales ratio. However, results on product or process innovation are not significant. The results are robust to alternative definitions of outcome variables and to a different definition of the control group. Additionally, the evidence suggests that the effect on firms' innovative intensity comes exclusively from small and young firms. Finally, the recurrence in accessing the program does not seem to have an additional effect.

This paper contributes to the existing literature in three different ways. First, it provides an accurate estimation of the effect of NRG since the control group is composed by firms that requested for public support, but were rejected. Previous articles define the control group as those firms that were not beneficiaries, whether or not they applied for public support of FONTAR ${ }^{1}$. Second, the paper provides results that correspond to the recent history of FONTAR since we analyze the period 2007-2013. Previous articles refer to benefits granted in the early 2000s or before. Thirdly, to the best of our knowledge, this is the first paper that finds effects on innovation intensity ratios instead on effects on innovative investments measured in absolute values ${ }^{2}$. Finally, the paper explores some non-linearities in the effect of FONTAR considering the age and the size of the firms as well as explores the role of recurrence in the participation in FONTAR. These findings allow policy makers to attain a better understanding of the mechanisms through which the program operates.

The rest of the paper is structured as follows. Second section presents a detailed description of the program. The third section describes the database on which the analysis is carried out and descriptive statistics are presented. In the fourth section, the econometric methodology to evaluate the impact of the program is developed. Section five contains the results and the discussion of the estimated results. Finally, in the last section the conclusions are developed.

1 Chudnovsky et al. (2006) and López et al. (2010) have expressed their concern about this definition of the control group.

2 It is worth to highlight that innovative investment measured in absolute levels can be affected by the firms' size. In turn, the ratio of innovation activities to sales is not affected by the size and is related to the innovative behaviour of the firm. Thus, the second definition is more accurate to study the effect of public policy on innovation efforts. 


\section{FONTAR AND THE NRG INSTRUMENT}

FONTAR is the main source of public funding for innovation at the firm level in terms of both the number of instruments and the amount of the grants (Porta and Lugones, 2011). It is administered by the ANPCyT, which depends on the MINCyT. The Fund was established in 1992 and subsequently ratified and re-funded by the following governments -from the most Neo-liberal to the most protectionists. The number of financing instruments, the average level of grants, and the types of funded projects had a strong stimulus in 2003, when the economic crisis was overcome and a new model based on a strong public intervention was implemented. As a result, the number of beneficiaries and projects has increased significantly since 2003 . The program is financed by the National Treasury, mostly from loans from the Inter-American Development Bank.

The objective of the fund is to foster innovation as a mean of promoting national competitiveness at the firm level, based on a horizontal comprehension of public policy - meaning that it is not a sectorial funding. It is organized around three types of instruments: non-refundable grants, tax credits and subsidized loans (NRG, TC and SL, respectively). NRG are orientated to co-fund high-risk projects orientated to the research and development of technological knowledge at the laboratory, prototype and pilot scales. Over the years, different specific calls have been launched with the aim of promoting strategic activities or sectors such as the NRGs for biotechnology, nanotechnology and information technologies, NRG patents, NRG R\&D, and NRG clean production. TC is the standard promotional instrument orientated to foster R\&D and technological modernization. It includes investments in the creation of productive and innovative capabilities at the firm level on the basis on an ex-post tax incentive. Finally, SL are cheap credits (in some years the interest was less than $10 \%$ of the interest rate of the market) aim to co-fund innovation projects with low technological risk, which means that the bulk of the project consists of incorporating embodied (and already proven) technology, with the correspondent investments in plant lay-out and human resource capabilities.

Specifically, the NRG finances up to $50 \%$ of the cost of the technological innovation project. The funds are only distributed when the Agency approves, technically and financially, the completion of the corresponding stage of the project. This means that it only grants the funds as a refund of the investment in effective innovation already made by the firm. For these projects, an ad hoc evaluation committee analyzes the technical quality and feasibility of the project, its economic viability, the technical capacity of the company and its economic and financial conditions.

According to the administrative records of FONTAR, the number of beneficiaries was approximately 1,900 between 2008 and 2012. Table 1 presents the evolution of granted firms considering both the three lines (i.e., NRG, TC and SL) and the NRG line. FONTAR program (through its different line of instruments) awarded 2,890 projects for more than US\$400 million. In turn, considering the NRG line exclusively, FONTAR program gave financial support 
to 1,541 projects of an amount of US\$108 million. This show the relevance of the analyzed instrument: although the NRG line concentrates almost $30 \%$ of the amount of funds allocated to firms, it explains more than the $50 \%$ of the granted projects.

\section{DATA AND DESCRIPTIVE STATISTICS}

To build the database we combined two sources of information. First, we use the administrative records of FONTAR with the population of firms that applied for public support to innovate, were they granted or not. Second, we use the innovation surveys applied to all the firms that requested for a financing instrument administered by FONTAR.

The first source of information is a two-dimensional panel database on innovation projects by firm and year from 2008 to 2012. This database includes information of the innovation project such as the year of presentation, the type of promotional instruments (SL, TC or NRG), the result of the request (i.e, if the firm was granted or not), as well as the traditional economic and structural indicators such as location and age.

The second source of information is a traditional CIS-type survey that began to be implemented in 2007. Regarding the group of beneficiary firms, the survey is conducted in two points of time: $i$ ) when the firm applies to FONTAR and ii) two years after the finalization of the innovation project. On each of these opportunities, the firm must answer the questionnaire considering the current and the previous two years. This guarantees the availability of information for before and after the reception of the benefit. Regarding the group of non-beneficiary firms, the survey is conducted only when they request for an innovation support. As with the group of beneficiary firms, they provide information related to the contemporaneous and the previous two years. The absence of legal impediments

TABLE 1

NUMBER OF AWARDED PROJECTS AND AMOUNTS FOR FONTAR AND THE NRG INSTRUMENT. 2008-2012

\begin{tabular}{|cccccc|}
\hline & \multicolumn{2}{c}{ FONTAR } & & \multicolumn{2}{c|}{ NRG instrument } \\
\cline { 2 - 3 } \cline { 5 - 6 } & \# projects & $\begin{array}{c}\text { Amount (millions } \\
\text { of USD\$) }\end{array}$ & & \# projects & $\begin{array}{c}\text { Amount (millions } \\
\text { of USD\$) }\end{array}$ \\
\cline { 1 - 2 } 2008 & 695 & 112.50 & & 328 & 21.33 \\
2009 & 315 & 33.16 & & 105 & 5.77 \\
2010 & 558 & 44.95 & & 308 & 18.49 \\
2011 & 652 & 69.97 & & 425 & 30.49 \\
2012 & 670 & 141.05 & & 375 & 31.93 \\
& 2,890 & 401.63 & & 1,541 & 108.01 \\
\hline
\end{tabular}

Source: Own elaboration based on ANPCyT survey data. 
to reapply for funding to innovate after the rejection of the grant, implies that within the group of non-beneficiary firms the rate of recurrence is very high. Hence, observations for non-beneficiary firms in the sample may exceed the three years ${ }^{3}$. Finally, given the fact that firms can request for a non-refundable grant in more than one opportunity we must consider the possibility that firms declare information related to a particular year more than once. In this case, we use the last information under the assumption that is the most updated estimation. Finally, regarding the survey, the questionnaire aims at gathering information about innovation and R\&D investments, qualified human resources, innovation results, employment, exports and sales.

The result of the integration of these two databases is a panel data made up of 2,101 which includes information for the period 2007 to 2013 related to firms that applied for some type of funding from FONTAR between 2008 and 2012 (FONTAR database).

As it was mentioned in the introduction, this paper aims at evaluating the effect of NRG instrument on firms' innovative performance. The FONTAR database includes information of firms that request for a public support applying to NRG, TC or SL. To build the treatment and control group we fully exploit the possible combinations of instruments. On the one hand, the treatment group is composed by firms that were beneficiaries only through NRG. On the other hand, the control group consists of those firms that applied for a public support but did not obtain it, that is, they were not beneficiaries of any of the instruments of FONTAR ${ }^{4}$. According to the definition of control group, it is possible to guarantee that the treatment and control group do not differ in at least one pre-existing relevant characteristic: the motivation that make them reveal their preferences for receiving public funds for innovation expenditures. As we stressed before, previous studies have built the control group including firms that never applied for public support which cast doubts on their counterfactual estimation given that most innovative firms are the most interested in applying for programs that support these activities ${ }^{5}$. In this line, López et al. (2010) explicitly states their concerns about not having a control group like ours, in their own words: "Ideally, the control group would be composed by firms that applied for subsidies but resulted unsuccessful" (p. 9) ${ }^{6}$.

3 In case of only one request, although those firms cannot act as control for that year call, they do for other years calls.

4 It is worth mentioning that the treatment group includes firms that may have applied for TC or SL. Regarding the control group, the group of firms that exclusively apply to NRG is less than $15 \%$ since firms often apply for a combination of instruments. However, in section 5.2 we consider an alternative definition of control group to check the robustness of results.

5 Klette et al. (2000) and David and Hall (2000) criticize the identification assumption of the majority of evaluations since not all firms are aware of public programs and, hence, do not apply for them (self-selection bias). Our criterion directly deals with this issue.

6 Also: "The fact that did innovation is unbalanced between groups might confirm our concern about not having identified the group of unsuccessful applicant firms: apparently, 
With the aim of creating a homogeneous and consistent database, we exclude companies that present extreme values (or no information) in some relevant variables such as innovation expenditures, sales and employment. In order to homogenize groups, we also filter those companies belonging to provinces that do not include beneficiary firms. Finally, as regards the control group, we requested information from other funds besides FONTAR to exclude those firms that received other funds from MINCyT during the analyzed period. This way, we reach a final panel database (unbalanced) between 2007 and 2013 with information on 954 firms and 2,868 firm-year observations. Of the total number of firms, 425 companies were beneficiaries of the NRG line between 2008 and $2012^{7}$ (Table 2), while the rest constitute the control group.

TABLE 2

NUMBER OF BENEFICIARY FIRMS BY YEAR

\begin{tabular}{|cc|}
\hline Year & \# firms \\
\hline 2008 & 63 \\
2009 & 67 \\
2010 & 80 \\
2011 & 121 \\
2012 & 94 \\
Total & 425 \\
\hline
\end{tabular}

Source: Own elaboration based on ANPCyT survey data.

Note: In case of more than one NRG, we consider the first one.

Table 3 shows the distribution of both the beneficiary and control groups according to size and age. Considering both variables, the comparison between groups reveals a homogeneous distribution. Regarding the size, it can also be appreciated that most of firms that apply for a FONTAR support are small.

Table 4 shows descriptive statistics of both treatment and control group within the pre-treatment period. These figures reveal that both groups are similar in most of the observable characteristics. However, beneficiary firms are larger, more prone to export and spend a greater proportion of their sales in innovation activities (IA) and R\&D than the firms in the control group. It is worth noting that the similarity in the "Product or process innovation" variable reflects the suitability of the control group: as both groups applied for funding for innovation they share the characteristic of having a high probability of innovating. Finally, we do not find significant differences between groups considering the

the firms that are eventually supported for developing innovations are the ones that before treatment were more likely to perform innovations" (p. 10).

7 We just consider adjudications with at least one year for the previous/posterior treatment period. 
TABLE 3

TREATMENT AND CONTROL GROUPS: SIZE AND AGE OF FIRMS

\begin{tabular}{|c|c|c|c|c|}
\hline & \multicolumn{2}{|c|}{ Control group } & \multicolumn{2}{|c|}{ Beneficiaries of a NRG } \\
\hline \multicolumn{5}{|l|}{ Size } \\
\hline Small & 436 & $82 \%$ & 332 & $78 \%$ \\
\hline Medium and large & 93 & $18 \%$ & 93 & $22 \%$ \\
\hline \multicolumn{5}{|l|}{ Age } \\
\hline Less than 10 years & 314 & $59 \%$ & 233 & $55 \%$ \\
\hline 10 or more years & 215 & $41 \%$ & 192 & $45 \%$ \\
\hline Total & \multicolumn{2}{|c|}{529} & \multicolumn{2}{|c|}{425} \\
\hline
\end{tabular}

Source: See Table 1.

Note: Small group includes firms with less than or equal 50 employees. Medium and Large group includes firms with more than 50 employees.

ratio of qualified human resources or the presence of a formal R\&D department in the firm.

\section{EMPIRICAL STRATEGY}

The main problem when evaluating the causal effect of the NRG line is that firms decide to participate in it. That is, the allocation of funds is not random. Therefore, it is necessary to use non-experimental methods to estimate the effects of the program on the innovative performance of beneficiary firms (Angrist and Pischke, 2009). Specifically, we use a difference-in-differences approach which compares changes in the outcome variable for the treatment and control groups before and after the intervention. This methodology is advantageous not only for its analytical simplicity but also for its effectiveness in avoiding potential endogeneity problems. These arise since we are dealing with firms with nonobservable heterogeneous characteristics, such as the entrepreneurship or the entrepreneurial ability ${ }^{8}$, which could be systematically correlated with program participation and with certain results in the outcome variables. The fixed effects (FE) model controls all the unobservable factors provided that they do not vary in time. As long as it is reasonable to assume that the program's selection criteria are based on relatively constant characteristics, the identification strategy can be considered acceptable for assessing the impact of the NRG line on the outcomes of interest.

Formally, the identification assumption of this model is that the potential outcome expectation in the absence of the program is independent of the treatment

8 Potential differences in motivation of firms are taken into account in the definition of the groups: both are constituted by firms that apply to receive public funds to finance innovation expenditures. 


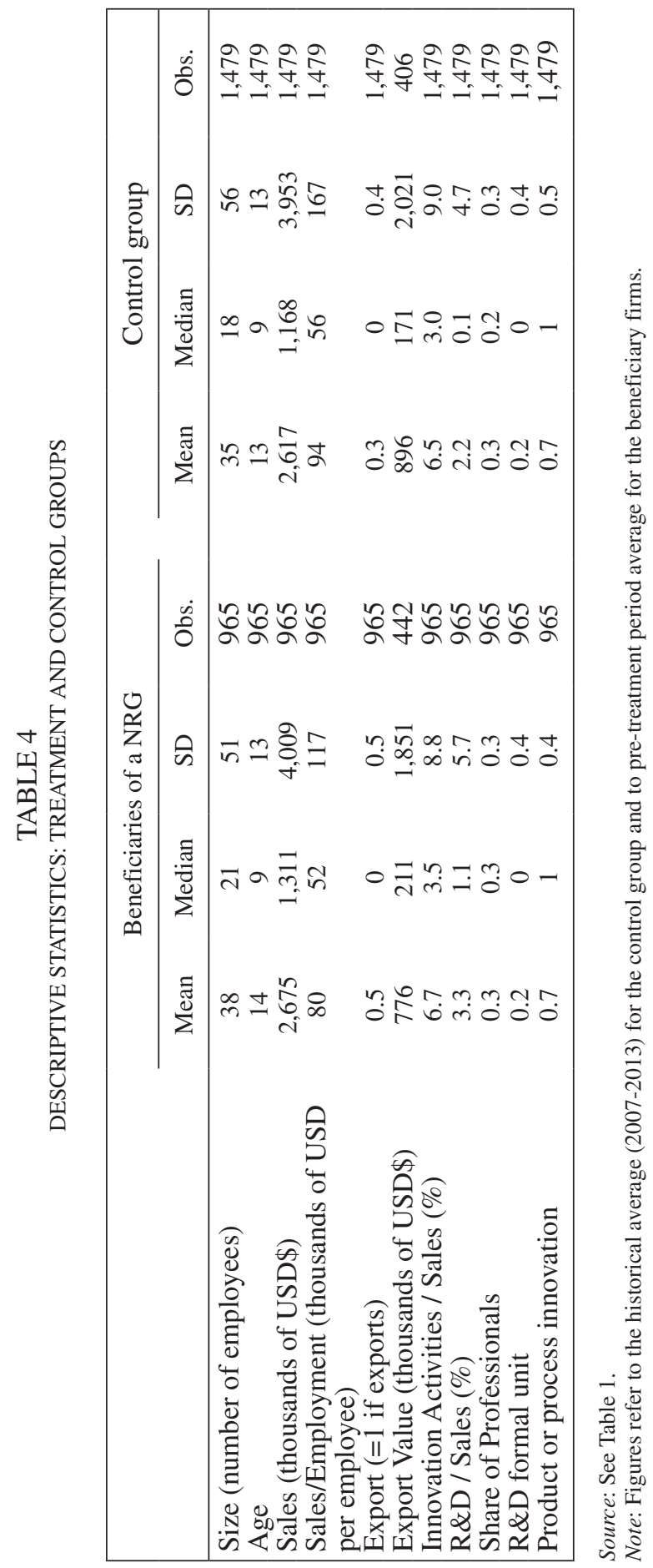


once considered the unobservable fixed effects and observable characteristics (Angrist and Piscke, 2009); i.e.:

$$
E\left(Y_{0 i t} \mid i, X_{i t}, t, D_{i t}\right)=E\left(Y_{0 i t} \mid i, X_{i t} t\right)
$$

This assumption implies that in the absence of the program, the trends in the control group and the counterfactual (beneficiary firms without treatment) would have been the same (common trends assumption).

According to Kim and Imai (2017), the ability of unit fixed effects models to adjust for unobserved time-invariant confounders comes at the expense of dynamic causal relationships between treatment and outcome variables. In particular, they highlight the two causal identification assumptions required under fixed effects models which are often overlooked by applied researchers: (1) past treatments do not directly influence current outcome, and (2) past outcomes do not affect current treatment.

To estimate the effect of the NRG line we use the following regression model:

$$
Y_{i t}=\alpha_{i}+\lambda_{t}+\gamma_{p t}+\beta D_{i t}+\delta X_{i t}+\varepsilon_{i t}
$$

Where $Y_{i t}$ represents the outcome variable considered for firm i in the year $\mathrm{t}, \alpha_{i}$ is the firm fixed effect ${ }^{9}, \lambda_{t}$ represents yearly shocks that affect all firms likewise, $\gamma_{p t}$ is a vector of interactions terms that includes province-year effects such as the construction of a route, an airport, the implementation of local policies, etc., $D_{i t}$ is a binary variable that takes value one from the year following the NRG's approval for firm i, $X_{i t}$ is a vector of control variables that vary over time, and $\varepsilon_{i t}$ is the error term that is assumed non-correlated with $D_{i t^{*}}$ In the absence of time-varying unobservable effects that affect both the allocation of the treatment and the outcome variable, the model consistently estimates the $\beta$ parameter, which captures the average effect of the NRG line on the considered outcome variable. Finally, standard errors are clustered at the firm level so that the statistical inference be robust regarding the serial correlation in the error term of each firm (Bertrand et al., 2004).

\section{Results: Causal Inference on Public program participation}

\subsection{Effects on firms' innovative performance}

Table 5 shows the estimated results of equation (2). The first and second column indicates the estimation of average treatment effect on the IA-sales and R\&D-sales It also absorbs fixed heterogeneity over time at three levels: sector, localization and
province. 
TABLE 5

ESTIMATED EFFECT OF FONTAR PROGRAM

\begin{tabular}{|lccc|}
\hline & $\begin{array}{c}\text { IA/sales (\%) } \\
\text { (I) }\end{array}$ & $\begin{array}{c}\text { R\&D/sales (\%) } \\
\text { (II) }\end{array}$ & $\begin{array}{c}\text { Product or Process } \\
\text { innovation } \\
\text { (III) }\end{array}$ \\
\hline NRG - FONTAR & $1.117^{*}$ & $1.056^{* *}$ & -0.0586 \\
age & $(0.645)$ & $(0.442)$ & $(0.0401)$ \\
age2 & 0.166 & 0.156 & $0.0534^{* * *}$ \\
R\&D formal unit & $(0.296)$ & $(0.165)$ & $(0.0193)$ \\
& -0.00548 & $-0.00405^{*}$ & -0.000307 \\
professionals/total & $0.00347)$ & $(0.00216)$ & $(0.000354)$ \\
employment & $0.554 *$ & 0.160 & $0.0622^{* * *}$ \\
& $(0.330)$ & $(0.210)$ & $(0.0221)$ \\
Observations & -0.0125 & 0.355 & $0.236^{*}$ \\
Number of firms & $(2.039)$ & $(1.215)$ & $(0.140)$ \\
Adjusted R-Squared & 2.868 & 2.868 & 2.868 \\
& 954 & 954 & 954 \\
& 0.0353 & 0.0608 & 0.0387 \\
\hline
\end{tabular}

*** Significant at the $1 \%$ level; ** significant at the 5\% level; *significant at the $10 \%$ level. Standard errors between brackets.

Note: NRG- FONTAR is a binary variable that takes the value one from the year following the NRG's approval. All the models are estimated through Ordinary Least Squares (OLS) and they include firm fixed effects and year fixed effects. Interaction terms between year and province dummies are also included as controls. The standard errors are calculated using clusters at the firm level.

ratios respectively. It would be desirable for the NRG line to have an impact on these variables since the program aims to foster the firms' innovative investment. Finally, the third column shows the estimated effect on innovation results.

Results confirm a positive and significant effect of FONTAR on innovative intensity. Specifically, beneficiary firms increased the IA-sales ratio by 1.11 percentage points $(\mathrm{pp})$ and the $\mathrm{R} \& \mathrm{D}$-sales ratio by more than $1.05 \mathrm{pp}$, relative to the control group ${ }^{10}$. Considering that IA investment includes R\&D, the evidence suggests that the program mainly fostered the investment on the latter one. To stress the economic relevance of these results we compare them to the pretreatment means of beneficiaries firms $(6.7 \%$ and $3.2 \%$ of IA/Sales and R\&D/ Sales respectively). According to these figures, estimated results represent an increase of $17 \%$ on IA intensity and $32.5 \%$ on the R\&D intensity ${ }^{11}$.

10 Considering the outcome variable in both absolute terms and logs we find positive and statistically significant effect. Nevertheless, these alternative definitions are biased by the firms' size.

11 We have information related to the private investment on innovative activities (i.e., net of the public benefit) for just 136 firms (32\% of the total beneficiary group). Therefore, we can not analyze the crowding-out effect. 
In summary, the set of results presented allows us to affirm that the public support helps to configure a group of firms characterized by a more virtuous innovative behaviour. Particularly, the NRG line shows a positive impact on the firms' investment on both $R \& D$ and total innovative activities. In spite of this, success in terms of the achievement of a new product or process is not guaranteed (Hujer and Radic, 2005; Patel and Pavitt, 1995). The third column of Table 5 shows that the probability of innovation results does not register changes after the participation in the public programme. This result can be explained by the small time window after the public support (less than five years to those firms granted in 2008): perhaps more time was needed for this dynamic innovative behaviour to underpin a better innovative performance in the market ${ }^{12}$.

\section{2. Robustness checks}

The effects that we found are the consequence of the implementation of the NRG, assuming that without it, the treatment group's innovative performance would have been similar to the control group's behavior. Although this assumption can not be directly tested, it is possible to test the similarity of the trends before the benefit: if the trends are the same in the previous periods, then it is likely that they would have been the same without the intervention. As suggested by Galiani et al. (2005), we estimate a variation of equation (1) using only pretreatment periods and including, instead of the treatment variable, interactions between year dummies and a dummy variable that is equal to one if the firm is eventually treated and zero otherwise ${ }^{13}$. Finding a not statistically significant estimate for these variables provides evidence in favor of the parallel trends assumption. As shown in Table 6 , for both the IA and R\&D expenditure intensity, none of the variables is statistically significant at the usual levels of statistical significance. In other words, we can not statistically reject the hypothesis that the pre-intervention year dummies are the same for the control group and the (eventually) treated firms, providing confidence for the difference-in-difference assumption.

Additionally, we study if the estimated results remain robust to variations in some specifications. First, we consider an alternative measure of firms' innovative intensity. This time, we construct the ratio of IA (and R\&D) expenditure to total employment (instead of total sales). Columns (I) and (II) of Table 7 show results that are in line with those already found: the impact on firms' innovative effort is positive compared to the counterfactual scenario. Specifically, an increase of 1.21 thousand dollars per employee can be attributable to the NRG awarded by FONTAR. Secondly, we redefine the control group. This time we

12 Considering separately product innovation and process innovation does not change the results.

13 We only use observations for the pre-treatment period: 2007-2012 for control group. In the case of beneficiaries we use pre-treatment observations from 2007 until they receive the benefit. 
TABLE 6

TEST OF PRE-TREATMENT TRENDS

\begin{tabular}{|lcc|}
\hline & $\begin{array}{c}\text { IA/sales }(\%) \\
(\mathrm{I})\end{array}$ & $\begin{array}{c}\mathrm{R} \& \mathrm{D} / \mathrm{sales}(\%) \\
(\mathrm{II})\end{array}$ \\
\hline $\mathrm{ANR} * 2007$ & 0.427 & -0.689 \\
& $(1.315)$ & $(0.600)$ \\
$\mathrm{ANR} * 2008$ & 0.153 & 0.454 \\
& $(1.049)$ & $(0.472)$ \\
$\mathrm{ANR} * 2009$ & 0.642 & 0.472 \\
& $(0.769)$ & $(0.409)$ \\
$\mathrm{ANR} * 2010$ & -0.228 & -0.00598 \\
& $(0.564)$ & $(0.329)$ \\
ANR*2012 & -0.277 & -0.876 \\
& $(0.884)$ & $(0.549)$ \\
Observations & 2,660 & 2,660 \\
Number of firms & 952 & 952 \\
Adjusted R-Squared & 0.0209 & 0.0456 \\
\hline
\end{tabular}

*** Significant at the $1 \%$ level; ** significant at the $5 \%$ level; *significant at the $10 \%$ level. Standard errors between brackets.

Note 1: The interactions are between the year dummies and a dummy indicating if the firm was eventually treated. Only pre-intervention observations are considered. All the models are estimated through Ordinary Least Squares (OLS) and they include firm fixed effects and year fixed effects. Interaction terms between year and province dummies are also included as controls. The standard errors are calculated using clusters at the firm level.

Note 2: The base group is the interaction between the group variable and the 2011 dummy, since this is the year with the greatest number of beneficiaries.

consider those firms that were only rejected in the NRG instrument ${ }^{14}$ (instead of rejected in any of the three types of instruments). Columns (III) and (IV) of Table 8 show that the effect on IA and R\&D remain positive and significant when considering this alternative group (1.4 pp and $1.15 \mathrm{pp}$, respectively). Looking Table 8 as a whole, we can affirm that empirical results are robust across different specifications of outcome variable and control group. Thus, these robustness checks support our previous conclusion about the causal effect of the NRG line on the innovation intensity.

\section{3. Heterogeneous effects}

Up to now we have presented the average effect of the NRG line for all firms that received the public support. However, the composition of the treatment group is very heterogeneous. For this reason, we test the presence of non-linearities related to the size and age within beneficiaries. This analysis helps to attain a

14 It is worth mentioning that these firms may have received a benefit from other instruments of program. 
TABLE 7

IMPACT OF THE NRG LINE. ROBUSTNESS CHECKS

\begin{tabular}{|c|c|c|c|c|}
\hline & \multicolumn{2}{|c|}{$\begin{array}{l}\text { Outcomes in relation } \\
\text { to employment }\end{array}$} & \multicolumn{2}{|c|}{$\begin{array}{c}\text { Control group: rejected only } \\
\text { in NRG }\end{array}$} \\
\hline & $\begin{array}{l}\text { IA/employ- } \\
\text { ment } \\
\text { (I) }\end{array}$ & $\begin{array}{c}\text { R\&D/employ- } \\
\text { ment } \\
\text { (II) }\end{array}$ & $\begin{array}{c}\text { IA/ sales }(\%) \\
\text { (III) }\end{array}$ & $\begin{array}{c}\mathrm{R} \& \mathrm{D} / \mathrm{sales} \\
(\%) \\
(\mathrm{IV})\end{array}$ \\
\hline NRG - FONTAR & $\begin{array}{l}121.4 * * \\
(55.19)\end{array}$ & $\begin{array}{l}48.38^{*} \\
(27.60)\end{array}$ & $\begin{array}{l}1.405 * * \\
(0.635)\end{array}$ & $\begin{array}{l}1.145^{* *} \\
(0.447)\end{array}$ \\
\hline age & $\begin{array}{l}40.00 \\
(26.42)\end{array}$ & $\begin{array}{c}25.12 * * * \\
(8.904)\end{array}$ & $\begin{array}{c}-0.00403 \\
(0.364)\end{array}$ & $\begin{array}{c}-0.0438 \\
(0.203)\end{array}$ \\
\hline age 2 & $\begin{array}{c}-0.618^{*} \\
(0.320)\end{array}$ & $\begin{array}{c}-0.366 * * * \\
(0.135)\end{array}$ & $\begin{array}{c}-0.00883 * * \\
(0.00380)\end{array}$ & $\begin{array}{c}-0.00463 * \\
(0.00280)\end{array}$ \\
\hline$R \& D$ formal unit & $\begin{array}{l}0.207 \\
(24.76)\end{array}$ & $\begin{array}{l}-13.50 \\
(11.24)\end{array}$ & $\begin{array}{c}0.423 \\
(0.362)\end{array}$ & $\begin{array}{c}0.251 \\
(0.266)\end{array}$ \\
\hline professionals/employment & $\begin{array}{l}911.8 * * \\
(427.4)\end{array}$ & $\begin{array}{c}113.4 \\
(105.9)\end{array}$ & $\begin{array}{c}0.365 \\
(2.139)\end{array}$ & $\begin{array}{c}0.858 \\
(1.780)\end{array}$ \\
\hline Observations & 2,868 & 2,868 & 1,651 & 1,651 \\
\hline Number of firms & 954 & 954 & 497 & 497 \\
\hline Adjusted R-squared & 0.0143 & 0.0235 & 0.0399 & 0.0198 \\
\hline
\end{tabular}

*** Significant at the $1 \%$ level; ** significant at the 5\% level; *significant at the $10 \%$ level. Standard errors between brackets.

Note: See Table 5.

better understanding of the public policy aimed to promote firms' innovative investment.

Table 8 presents estimations of the NRG's impact according to the size and age of the firms. Regarding the size, the Small group includes firms with less than or equal to 50 employees, and the Medium and Large group includes firms with more than 50 employees. Regarding the age, the Young group includes firms with less than or equal to 10 years in the market, and the Old group includes firms with more than 10 years.

The analysis of Table 8 reveals that the firms' innovative performance has increased exclusively among small firms (and not among the Medium and Large group). Specifically, in this group, both the innovative activities to sales ratio and R\&D to sales ratio are substantially greater than the ratios that would have been registered in the absence of public support (+1.59 pp and $+1.46 \mathrm{pp}$, respectively). Regarding to firms' age, we find that the impact of the NRG comes solely from Young firms (+2,86 p.p. on the IA-sales ratio and $+2,12$ p.p. on the R\&D-sales ratio). Is in this subgroup where we find the greatest impact.

In line with these findings, other studies show that that firms that combine newness, smallness, and high R\&D intensity are rare in the sample of innovative 


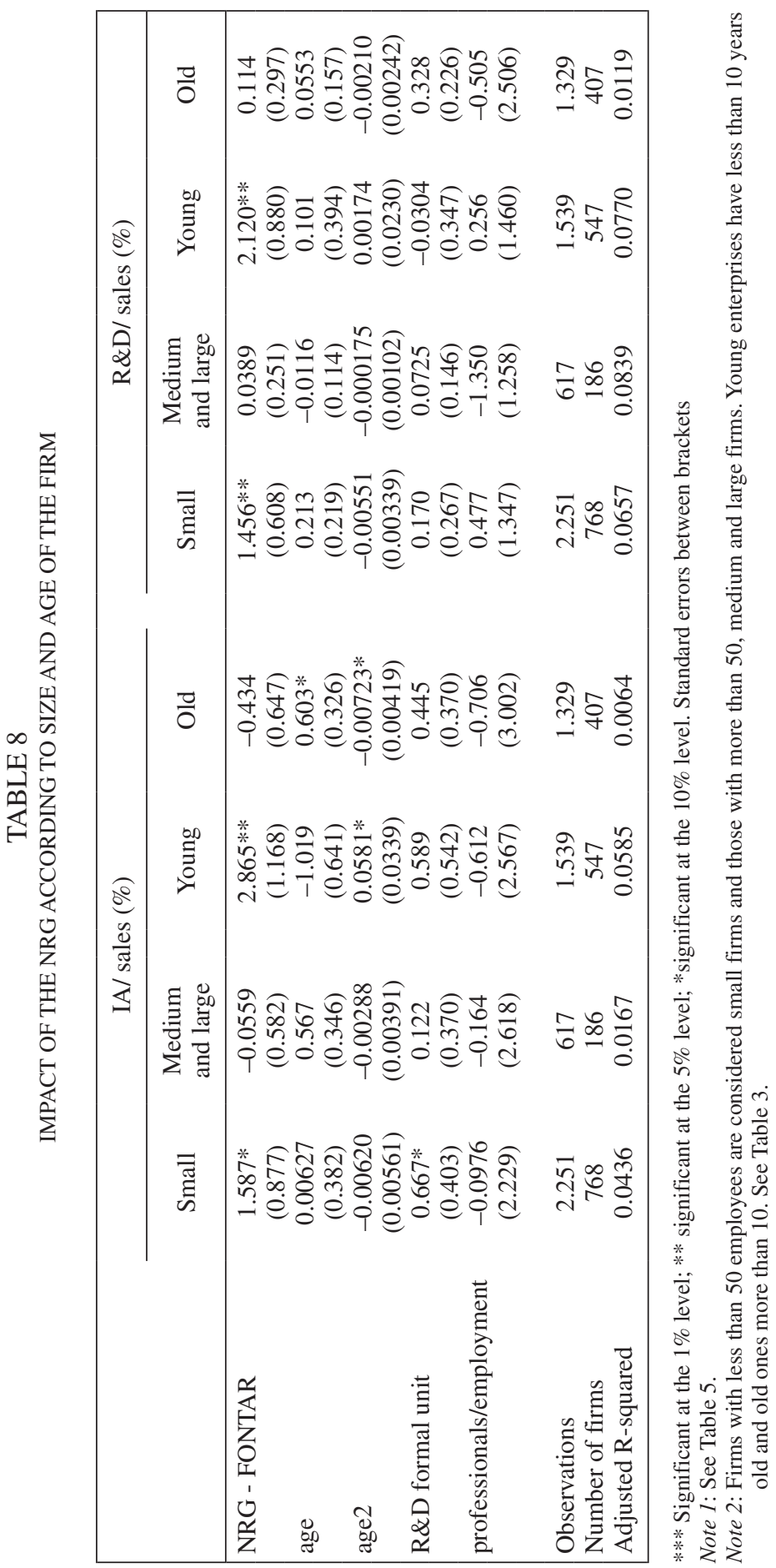


firms, but achieve significantly higher innovative sales than other innovative firms, especially innovative sales from products that are new to the market (Schneider and Veugelers, 2010).

In summary, these findings indicate that the causal effect of FONTAR was concentrated on small and young firms. This heterogeneous effect within beneficiary firms sheds some light on the groups of firms that are fully exploiting the benefits of the program. Since newly and small firms may face financing constraints leading to shelved projects, one may expect a larger average treatment effect for these firms (e.g. Czarnitzki and Hottenrott 2011; Cincera et al. 2014; Pellegrino et al, 2012; Schneider and Veugelers, 2010).

Finally, we focus on the recurrence in accessing the NRG line. That is, we test if the effect of public program differs between those firms that that were granted once and those that were granted twice or more. To do that we estimate equation (1) but employing a different treatment indicator for each group of beneficiaries. Estimated results (see Table 9) suggest that among recurrent firms the program do not exerts a positive impact on the innovative efforts. However, it is worth mentioning that within the period under analysis less than the one quarter of beneficiary firms were granted more than once. Thus, this result should be taken with caution due to the low participation of recurrent firms.

TABLE 9

IMPACT OF THE NRG ACCORDING TO RECURRENCE OF THE FIRM

\begin{tabular}{|lcc|}
\hline & $\begin{array}{c}\text { IA/ sales }(\%) \\
(\mathrm{I})\end{array}$ & $\begin{array}{c}\text { R\&D/ sales }(\%) \\
(\mathrm{II})\end{array}$ \\
\hline One NRG & $1.876^{* *}$ & $1.640^{* *}$ \\
& $(0.883)$ & $(0.640)$ \\
More than one NRG & 0.0258 & 0.217 \\
& $(0.752)$ & $(0.469)$ \\
age & 0.167 & 0.157 \\
& $(0.297)$ & $(0.167)$ \\
age2 & $-0.00571^{*}$ & $-0.00423^{*}$ \\
R\&D formal unit & $(0.00344)$ & $(0.00217)$ \\
& $0.564 *$ & 0.168 \\
professionals/employment & $(0.330)$ & $(0.210)$ \\
& -0.0825 & 0.301 \\
Observations & $(2.029)$ & $(1.206)$ \\
Number of firms & & 2.868 \\
Adjusted R-squared & 2.868 & 954 \\
\end{tabular}

Note 1: See Table 5.

Note 2: The original treatment variable is divided into two variables, one for companies that received a single NRG and other for those with more than one. 


\section{Conclusions}

The paper presented new micro-econometric evidence on the issue of public support to innovative activities in Argentina. In particular we analyzed the NRG line of the main instrument to foster innovation in the country: the FONTAR. We analyzed how this instrument affects the firms' innovative behavior. In addition, we also wonder if this effect might be affected by structural characteristics of the firm, or by the number of received benefits.

This is the first paper using a database stemming from innovation surveys carried out on firms that request for a public support to FONTAR. This helped to define the control group as those firms that applied but did not receive a benefit. Databases used in previous evaluations of FONTAR do not have this information. As a consequence, their control group includes firms that do not receive a support from FONTAR whether or not they applied for it. In summary, our results are based on a more accurate definition of counterfactual scenario.

Results confirmed the causal effect of FONTAR. That is, we found that the NRG exerts a positive and statistically significant effect on the intensity of innovative investments. In particular, $R \& D$ investment trigger the increase in total innovation activities. Compared to the pre-treatment mean of the outcome variable among beneficiaries, we found an increase of $17 \%$ in the IA-sales ratio and $32.5 \%$ in the R\&D-sales ratio. It is worth to highlight that these results remain robust to alternative definitions of both outcome variables and control group. We also found non-linearities within the group of beneficiary firms. In the first place, recurrence in accessing the program does not exert an additional effect. More importantly, the effect of FONTAR comes exclusively from small and young firms.

It is worth mentioning some limitations of this particular research. The main limitation has to do with the dataset. Since the panel does not include variables that capture the private investment on both R\&D and total IA, questions about the crowding in/out can not be answered. Additionally, since the panel does not include information about the sectorial composition of firms that request for a public support, questions about the presence of sectorial heterogeneity within beneficiary firms can not be answered neither. We expect that this paper stimulates public authorities to keep the efforts to improve the information requested by the survey.

Finally, results of our paper provide some policy recommendations. Firstly, the empirical evidence stresses the crucial role of NRG to stimulate the firms' investment on innovative activities. This result become strongly relevant considering the current outlook for technological policy in Argentina. The new administration decided to restrict the set of instruments administered by FONTAR to just SL (i.e., eliminating NRG). According to the evidence coming from this article the technological policy would face some difficulties to foster innovation in the private sector. Secondly, our results provide useful guidelines for a future redesigning of FONTAR. According to this paper we might think of making R\&D support conditional on firm age and size -focused more strongly 
on young and small firms, with older and medium/large firms being less eligible for this support. This refocusing of the main instrument to foster innovation at the private sector may improve their effect.

\section{REFERENCES}

Aschhoff, B. (2009). "The Effect of Subsidies on R\&D Investment and Success: Do Subsidy History and Size Matter?", ZEW Discussion Article no. 09-032, Centre for European Economic Research, Mannheim, Germany.

Aghion, P., and Howitt, P. (1990). "A model of growth through creative destruction (No. w3223).”, National Bureau of Economic Research (NBER).

Angrist, J., and J. Pischke (2009). Mostly harmless econometrics: an empiricists companion. Princeton University Press.

Bertrand, M., Duflo, E., and Mullainathan, S. (2004). "How much should we trust differences-in-differences estimates?", The Quarterly Journal of Economics, Vol. 119(1); 249-275.

Binelli, C., and Maffioli, A. (2007). "A Micro-econometric Analysis of Public Support to Private R\&D in Argentina", International Review of Applied Economics, Vol. 21(3); 339-359.

Chudnovsky, D., López, A., Rossi, M., and Ubfal, D. (2006). "Evaluating a program of public funding of private innovation activities: An econometric study of FONTAR in Argentina", Inter-American Development Bank.

Crespi, G., A. Maffioli, and U A. Rasteletti (2014). Investing in ideas: policies to foster innovation, in Rethinking productive development: sound policies and institutions for economic transformation, ed. by G. Crespi, E. Fernandez-Arias, and E. Stein, 61-106. Palgrave Macmillan.

Czarnitzki, D., \& Hottenrott, H. (2011). "R\&D investment and financing constraints of small and medium-sized firms", Small Business Economics, Vol. 36(1), 65-83.

David, P. and Hall, B. (2000). "Heart of darkness, public-private interactions inside the R\&D black box", Research Policy, Vol. 29 (9); 1165-1183.

Galiani, S., Gertler, P. and Schargrodsky, E. (2005). "Water for life: The impact of the privatization of water services on child mortality", Journal of Political Economy, Vol. 113(1); 83-120.

Grossman, G. M.,and Helpman, E. (1991). "Quality ladders in the theory of growth", The Review of Economic Studies, Vol. 58 (1); 43-61.

Kim, I. and Imai K. (2017). "When Should We Use Fixed Effects Regression Models for Causal Inference with Longitudinal Data?", Working Paper, Princeton University 2017.

López, A., Reynoso, A. M., and Rossi, M. (2010). "Impact Evaluation of a Program of Public Funding of Private Innovation Activities: An Econometric Study of FONTAR in Argentina", OVE Working Papers, Inter-American Development Bank: https://EconPapers.repec.org/RePEc:idb:ovewps:0310. 
Hujer, R. and Radic, D. (2005). "Evaluating the impacts of subsidies on innovation activities in Germany". Scottish Journal of Political Economy, Vol. 52 (4); 565-586.

Patel, P. and Pavitt, K. (1995). "Patterns of technological activity: their measurement and interpretation", in P. Stoneman (Ed.) Handbook of the Economics of Innovation and Technological Change, Oxford, Blackwell Publishers, 14-5.

Pelegrino G., Piva M. and Vivarelli M. (2012). "Young firms and innovation: A microeconometric analysis", Structural Change and Economic Dynamics, Vol. 23 (4), pp. 329-340.

Porta, F. y Lugones, G. (2011). Investigación científica e innovación tecnológica en Argentina. Impacto de los fondos de la Agencia Nacional de Promoción Científica y Tecnológica. Bernal: Universidad Nacional de Quilmes.

Romer, P. M. (1990). "Endogenous technological change", Journal of Political Economy, Vol. 98(5); 71-102.

Schneider C. and Veugelers R. (2010). "On young highly innovative companies: why they matter and how (not) to policy support them", Industrial and Corporate Change, Vol. 19 (4), 969-1007. 
